\title{
RHETORICAL STRUCTURE OF INTEGRATED RESULTS AND DISCUSSION CHAPTER IN MASTER'S DISSERTATIONS ACROSS DISCIPLINES
}

\author{
Zahra Shirian Dastjerdi \\ Helen Tan \\ Ain Nadzimah Abdullah
}

\begin{abstract}
Writing a dissertation is the most challenging task for students, especially the Integrated Results and Discussion chapter. One solution would be to offer them a template of the rhetorical flow of this chapter. However, to date, a limited number of studies have been conducted on the rhetorical movement of this chapter. Therefore, the rhetorical units of Integrated Results and Discussion chapters of 40 Master's dissertations in the hard and soft science disciplines obtained from a Malaysian local public university were investigated. The findings indicated that this chapter focused predominantly on presenting the results followed by commenting on them. Disciplinary variation was observed in the use of 'referring to previous research' and 'making overt claims or generalizations' which were observed more in the dissertations in the soft sciences. Besides, 'invalidating results' was found more in the dissertations in the hard sciences. To conclude, knowing the prevalent moves may heighten the awareness of novice postgraduate students to align their writing to the academic writing conventions. Furthermore, awareness on the disciplinary variations of the use of certain rhetorical moves would sensitize novice writers to the preferred disciplinary style of writing Integrated Results and Discussion chapter.
\end{abstract}

\section{Keywords}

genre analysis, Master's dissertation, rhetorical units, hard science disciplines, soft science disciplines

\section{Introduction}

Writing a dissertation as a specific genre is a challenging task for ESL students because of the linguistic complexities, the size of the text, and the high standards of language use that must be met in writing a dissertation (Thompson 2012, Dong 1998). This challenging task is particularly difficult for ESL students in writing Integrated Results and Discussion chapters of dissertations. In other words, ESL student writers are required not only to have the knowledge to write in the English language, but they should also be equipped with the necessary skills to "argue logically and coherently the meaning of the research results" (Dong 1998: 369). 
According to Thompson (2012), writing Results and Discussion chapter of dissertations is difficult for ESL students because of their unfamiliarity with the rhetorical conventions of the target language. According to Hyland (2004: 15), move analysis research assists to critically appraise texts and consequently, it raises ESL students" awareness of "how texts actually work as communication". Through recognizing move structure of Integrated Results and Discussion chapters of dissertations, authentic example and comprehensible text structures of this important chapter of dissertations will be provided to ESL student writers. Move analysis entails recognizing a series of rhetorical moves that constitutes discourse structure of a particular genre and consequently, each move performs its own particular communicative purpose.

In line with this understanding, Bhatia (2001: 84) argues that moves are "rhetorical instruments that realize a sub-set of specific communicative purposes associated with a genre". As such, recurrent particular moves and their presence in genre-specific texts enable move analyzers to distinguish between different genres (Swales 1990). Similarly, according to Upton and Connor (2001: 5), moves are identifiable because of their communication purposes and their rhetorical functions. In consequence, rhetoric function knowledge is of importance in writing convention. This importance is due to the role that rhetoric function plays in contributing to the overall communicative purpose of the text (Thompson 2012).

A number of move analysis studies have been conducted either on the Results section or Discussion sections of research articles (e.g. Brett 1994, Posteguillo, 1999, Nwogu 1997, Yang \& Allison 2003, Atai \& Falah 2005, Kanoksilapatham 2007, Fallahi \& Erzi 2003, Kanoksilapatham 2005); however, to the knowledge of the researchers, no study has investigated the rhetorical units of Integrated Results and Discussion chapter of theses as an emerging genre in corpus studies. Therefore, to fill this gap and to shed light on the rhetorical structures of Integrated Results and Discussion chapters of ESL students' writings, the present study analyzed Integrated Results and Discussion chapters of Master's dissertations written by ESL students in the soft science disciplines and hard science disciplines hereinafter referred to as SS and HS respectively.

Ebrahimi and Chan (2013: 31) discussed that an Integrated Results and Discussion chapter of a research can be entitled as "Results and Discussion". According to Stoller and Robinson (2013), in Integrated Results and Discussion, results are presented and simultaneously discussed in a seamlessly integrated argument and the argument may be included in a paragraph or even in a sentence. Even though the choice of adapting the structure of writing thesis chapters is left to students, they show more tendency to merge the two chapters into one. 
One possible reason is that in this structure, students do not have to make cross-references between specific parts of the result(s) and specific parts of discussion(s). On the other hand, from the reader's side, it is easier to read and follow the contents when the results and discussion are integrated.

\section{Method}

To achieve the above-stated objectives of the study, a mixed methodology of quantitative and qualitative paradigms was utilized. Descriptive statistics was utilized to obtain the necessary database in terms of computing and illustrating the frequencies of the employed rhetorical move and steps in the corpus. On the other hand, qualitative data was found to be useful in order to provide an in-depth description of the rhetorical movements of the examined texts.

Among the proposed models for move analysis of Results and Discussion (e.g. Swales 1990, Weissberg \& Buker 1990, Brett 1994, Yang \& Edwards 1995, Yang \& Allison 2003, Kanoksilapatham 2005, Holmes 1997, Hopkins \& DudleyEvans 1988, Posteguillo 1999), Kanoksilapatham's (2005) model was selected due to its comprehensiveness and up-to-dateness. Since no model was proposed to investigate Integrated Results and Discussion chapter of dissertations, Kanoksilapatham's (2005) models for Results section and for Discussion section were integrated and in order to improve the accuracy and reliability of the model, a pilot study was performed. The sectioning or sub-sectioning strategies of the texts which are performed under macro analysis of the texts (Schiffrin et al. 2003) are not taken into consideration.

The corpus of the pilot study consisted of eight dissertations. From these eight dissertations, two were from Chemistry, two from Physics, two from English, and two from Economics. The pilot study revealed that the merged model was compatible with the corpus of the study; however, two steps (Structure of Section and Pointer) which were borrowed from Brett's (1994) model and were missing in the initial models were added to the analytical framework of the study.

Besides, in order to improve the accuracy and reliability of the present study, two raters were consulted - they analyzed 20 dissertations taken from the main corpus of the study ( 5 from each discipline). Both raters have a $\mathrm{PhD}$ in Linguistics and both are experts in the area of discourse and genre analysis. The results of the raters' analysis were compared with the framework of the study. Inter-rater reliability was determined by comparing the researcher's color-coding with the co-raters' identification of the moves, noting agreements and disagreements on the presence and absence of each move. The percentage agreement was calculated using the formula $\mathrm{A} /(\mathrm{A}+\mathrm{D}) \times 100$ where $\mathrm{A}=$ the number of agreements and 
$\mathrm{D}=$ the number of disagreements. This method was used by some researchers (e.g. Arulandu 2006, Biber et al. 2007).

In this study, the percentage agreement was found to be 96.88 , which is an acceptable rate (Al-Zubaidi 2013, Biber et al. 2007). Where there were discrepancies, a consensus was reached after a discussion with the raters. In the case of a disagreement, a vote was taken. In other words, two agreements were needed to confirm a step as a rhetorical pattern or as a specific part of the analytical model.

Forty dissertations' Integrated Results and Discussion chapters were used as the sample of the study. Twenty of the dissertations were selected from the HS disciplines (ten from Physics and ten from Chemistry) and twenty of the dissertations were selected from the SS disciplines (ten from English and ten from Economics). The total word number of the corpus of the present study is 200,000 , which was identified as a reasonable corpus worthy of investigation (Ooi 2001, Kennedy 1998). Due to ethical issues, the title of the dissertations and the name of the authors are kept confidential. Additionally, a permission letter was obtained from the university which holds the copyright of the dissertations.

The analysed dissertations were written by ESL students and contained an Integrated Results and Discussion chapter. The investigated Integrated Results and Discussion chapters were mostly the fourth chapter of Master's dissertations from the years 2002 to 2012. It should be noted that the guidelines proposed by the university did not mention details such as the rhetorical organization of the dissertations. They only presented the overall organization of the dissertations.

$\mathrm{PhD}$ theses were not chosen as the corpus of the study, because they are long texts, running up to 100,000 words in length, and they are also difficult to obtain as there are usually not many dissertations written in any one department, at a single university. There may be errors in students' writings (Al-Buainain 2011); however, error analysis is not in the scope of the present study. Another justification for choosing Master's dissertations as the corpus of this study is that in the study by Arulandu (2006), it was revealed that the use of similar rhetorical and linguistic strategies was similar between the Master's and $\mathrm{PhD}$ dissertations.

In addition, this study specifically focused on the dissertations from one institution because the researcher, as a student at the same university, was familiar with the site and staff. This justification was also echoed by Kennedy (1998), who underlined the importance of accessibility and availability of the corpus in conducting discourse analysis.

Additionally, Paltridge (2002: 17) argued that since the beginning decades of the 21 st century, public university students have become diverse in terms of "race, gender, nationality and economic background". In line with this argument, 
Duderstadt (2000: 22) emphasized that in the $21^{\text {st }}$ century, since students of public universities "come from different backgrounds", they have the capabilities of performing research with "different intellectual objectives". Duderstadt (ibid.) concluded that a single public university may provide a diverse population for data gathering purpose.

\subsection{Data analysis procedures}

In order to carry out the analysis, firstly, attempts were made to describe the patterns of the rhetorical moves and steps in the corpus of the study. Secondly, it was endeavored to demonstrate how the patterns of rhetorical moves and steps in the examined corpus differ between the HS and SS disciplines. To achieve these objectives, the researcher gained an in-depth insight of the corpus by a thorough perusal of the whole corpus. Then, the rhetorical moves and steps of the corpus were highlighted in the light of the analytical framework of the study. As such, all the Integrated Results and Discussion chapters of the dissertations of the study were read once again sentence by sentence. Some sentences were found to have complex structures and contained more than one communicative purpose. In such cases, the steps in a complex sentence were analyzed and discussed as different units of rhetoric. After identifying a step in the whole corpus, a descriptive account of the function of that specific step was presented.

Finally, the frequencies of occurrence(s) of the identified moves and steps were computed and tabulated. Research has shown that a move or step can be either optional or obligatory (Kanoksilapatham 2005, Yang \& Allison 2003, Brett 1994). As a rule of thumb, Li (2011) concluded that those moves which occur more frequently can be considered as obligatory and those that happen less frequently can be evaluated as optional. In line with Kanoksilapatham (2005: 2007), if a step was found in 60 per cent or more than 60 per cent of the number of the texts (in this study 12 or more than 12 out of 20 for each science), that step was considered as an obligatory one and if the occurrence number of a step was less than 60 per cent of the total number of the investigated texts, then that step was considered as an optional one. This method of analysis is also attested by Biber et al. (2007).

\section{Results}

Table 1 is an illustration of the corpus' rhetorical movements in the HS and SS. 


\begin{tabular}{|l|c|c|c|c|}
\hline \multirow{2}{*}{ Moves (M) } & \multicolumn{2}{|c|}{ HS } & \multicolumn{2}{c|}{ SS } \\
\cline { 2 - 5 } & No. & $\%$ & No. & $\%$ \\
\hline M1: Structure of the Section & 19 & 1.43 & 60 & 4.05 \\
\hline M2: Stating Procedures & 159 & 11.94 & 222 & 15.00 \\
\hline M3: Justifying Procedures or Methodology & 85 & 6.38 & 85 & 5.74 \\
\hline M4: Stating Results & 484 & 36.34 & 479 & 32.36 \\
\hline M5: Stating Comments on the Results & 275 & 20.65 & 306 & 20.68 \\
\hline M6: Contextualizing the Study & 195 & 14.64 & 170 & 11.49 \\
\hline M7: Consolidating Results & 105 & 7.88 & 147 & 9.93 \\
\hline M8: Stating Limitations of the Present Study & 6 & 0.45 & 11 & 0.74 \\
\hline M9: Suggesting Further Research & 4 & 0.30 & 0 & 0 \\
\hline Total & 1332 & 100 & 1480 & 100 \\
\hline Total number of moves & & & 2812 & \\
\hline
\end{tabular}

Table 1: Distribution of rhetorical moves across HS and SS

As seen in Table 1, M4 followed by M5 have the highest frequency in both the HS and SS disciplines. The high frequency of M4 and M5 shows that the main functions of Results and Discussion chapter are to present the results (M4) and comments on the results (M5). This result is congruent with Ebrahimi and Chan's (2013: 30) study, who opined that this chapter presents and highlights the results and comments on them. The high frequency of M4 and M5 was also attested by Kanoksilapatham (2005), who stated that the main function of a Results and Discussion section is objective presentation of results (M4) and simultaneously providing subjective comments on them (M5).

Furthermore, the high frequency of occurrence of M4 is attested by Brett (1994) in the SS. Brett (1994: 47) argued that repeated occurrences of the rhetorical move are in line with the purpose of presenting results of a study. On the other hand, the lowest frequently found moves were M8 and M9. This low frequency of M9 and M8 is not surprising as the Conclusion chapter is normally provided for writers to discuss the limitation of the study and recommendation for further research (Thompson 2005). 


\subsection{Steps of rhetorical moves}

The data also revealed that the rhetorical movement of the Integrated Results and Discussion chapter is not limited to just the move levels but there were steps in some of the rhetorical moves. Another remarkable overall illustration of the study's finding is the obligatory and optional status of the rhetorical movements (cf. Table 2).

\begin{tabular}{|c|c|c|c|c|c|}
\hline \multirow[t]{2}{*}{ Moves } & \multirow[t]{2}{*}{ Steps } & \multicolumn{2}{|c|}{ HS } & \multicolumn{2}{|c|}{ SS } \\
\hline & & No. & $\%$ & No. & $\%$ \\
\hline M1 & Structure of Section & 15 & 75 & 20 & 100 \\
\hline \multirow[t]{4}{*}{ M2 } & M2S1: Describing Aims and Purposes & 16 & 80 & 16 & 80 \\
\hline & M2S2: Stating Research Questions & 0 & 0 & 4 & 20 \\
\hline & M2S3: Making Hypotheses & 1 & 5 & 2 & 10 \\
\hline & $\begin{array}{l}\text { M2S4: Listing Procedures/Methodological } \\
\text { Techniques }\end{array}$ & 20 & 100 & 20 & 100 \\
\hline \multirow[t]{2}{*}{ M3 } & $\begin{array}{l}\text { M3S1: Citing Established Knowledge of the } \\
\text { Procedure }\end{array}$ & 18 & 90 & 16 & 80 \\
\hline & M3S2: Referring to Previous Research & 8 & 40 & 16 & 80 \\
\hline \multirow[t]{3}{*}{ M4 } & M4S1: Pointer & 20 & 100 & 20 & 100 \\
\hline & M4S2: Substantiating Results & 20 & 100 & 20 & 100 \\
\hline & M4S3: Invalidating Results & 12 & 60 & 10 & 50 \\
\hline \multirow[t]{5}{*}{ M5 } & M5S1: Explaining the Results & 18 & 90 & 20 & 100 \\
\hline & $\begin{array}{l}\text { M5S2: Making Generalizations/Interpretations of } \\
\text { Results }\end{array}$ & 20 & 100 & 20 & 100 \\
\hline & $\begin{array}{l}\text { M5S3: Evaluating Findings with Previous Studies/ } \\
\text { Hypotheses }\end{array}$ & 16 & 80 & 16 & 80 \\
\hline & M5S4: Stating Limitations & 2 & 10 & 0 & 0 \\
\hline & M5S5: Summarizing & 2 & 10 & 9 & 45 \\
\hline \multirow[t]{2}{*}{ M6 } & M6S1: Describing Established Knowledge & 19 & 95 & 19 & 95 \\
\hline & $\begin{array}{l}\text { M6S2: Presenting Generalizations/Claims/ } \\
\text { Deductions/Research Gaps }\end{array}$ & 10 & 50 & 11 & 55 \\
\hline
\end{tabular}




\begin{tabular}{|l|l|l|l|l|l|l|}
\hline \multirow{2}{*}{ Moves } & \multirow{2}{*}{ Steps } & \multicolumn{2}{|c|}{ HS } & \multicolumn{2}{c|}{ SS } \\
\cline { 3 - 7 } & & No. & $\%$ & No. & $\%$ \\
\hline \multirow{4}{*}{ M7 } & M7S1: Restating Methodology & 4 & 20 & 8 & 40 \\
\cline { 2 - 7 } & M7S2: Stating Selected Findings & 9 & 45 & 2 & 10 \\
\cline { 2 - 7 } & M7S3: Referring to Previous Literature & 18 & 90 & 12 & 60 \\
\cline { 2 - 7 } & M7S4: Explaining Differences in Findings & 3 & 15 & 10 & 50 \\
\cline { 2 - 7 } & M7S5: Making Overt Claims or Generalizations & 9 & 45 & 18 & 90 \\
\cline { 2 - 7 } & M7S6: Exemplifying & 2 & 10 & 11 & 55 \\
\hline \multirow{3}{*}{ M8 } & M8S1: Limitations about the Finding & 0 & 0 & 2 & 10 \\
\cline { 2 - 7 } & M8S2: Limitations about the Methodology & 4 & 20 & 4 & 20 \\
\cline { 2 - 7 } & M8S3: Limitations about the Claims Made & 0 & 0 & 1 & 5 \\
\hline \multirow{2}{*}{ M9 } & Suggesting Further Research & 2 & 10 & 0 & 0 \\
\hline
\end{tabular}

Table 2: Obligatory and optional moves and steps

According to Table 2, rhetorical units of M1, M2S1, M2S4, M3S1, M4S1, M4S2, M5S1, M5S2, M5S3, M6S1, and M7S3 were found to have 60 per cent or more of occurrences in the HS or SS disciplines. Therefore these steps were considered obligatory. Besides, disciplinary variations were observed in M3S2, M4S3, and M7S5. In the HS disciplines, M3S2 and M7S5 were obligatory. But they were found to be optional in the SS disciplines. On the other hand, in the SS discipline, M4S3 was obligatory, but in the HS disciplines, it was optional.

\subsection{Functions and forms of rhetorical movements}

In order to provide an insight into the nature of the rhetorical units of the texts, a detailed description of each rhetorical unit identified in the data is presented in the following section. In addition, excerpts from the corpus are presented to clarify the moves/steps.

M1: Indicates the order and content of the text which follows (Brett 1994: 52):

(1) This chapter also presents the finding and discussion of the study ... (Economics)

In both sciences, M1 was found to be obligatory (HS: 75\%; SS: 100\%). 
All the dissertations written in the SS used this move in order to present the organization of their chapters. However, in the HS, this move was not found in five dissertations. The fact that M1 was found in all the dissertations in the SS is synonymous with the study of Brett (1994), who also found M1 in articles of Sociology. As another finding of the present study, it was found that M1 was mostly used at the beginning of the chapters to present the order of the contents of the chapter. However, in seven cases (out of 40 dissertations) it was found at the end of the chapter to explain the contents of the next chapter.

M2: Describes why and how the data of the study have been produced. The frequency of occurrence of this move was 159 in the HS and 222 in the SS. The high frequency of occurrence of this rhetorical unit is explicable in terms of students' concern about the validity of their research findings, which is also attested by Salmani Nodoushan (2011). This rhetorical move is also reported by Kanoksilapatham (2005). She mentioned that such a rhetorical structure can be used to emphasize some important information about the preceding methods section. According to Kanoksilapatham (ibid.), the move also aimed at preparing the readers for the other moves which focus on the results of the study.

M2S1: Explains the aims and purposes of the study:

(2) This study examines the costs and economic impacts of CoC certification based on the survey done on certified sawmills in Malaysia in year 2006 and 2007. (Economics)

This step was found in 16 dissertations (80\%) both in the HS and SS disciplines and consequently evaluated to be obligatory. A plausible reason for the presence of this step in most of the dissertations in the HS and SS disciplines is that before the argument of the Results and Discussion could take place, the aim of the study needed to be explicitly stated. Therefore, in the Integrated Results and Discussion chapter, preparation of ideas is necessary and is one of the features of cohesion in successful writing.

M2S2: States the research questions of the study:

(3) Do learners improve in general pronunciation (all sounds in English) using the scaffolding-based software? (English) 
In this study, M2S2 was found to be an optional step both in the HS and SS disciplines. Only 20 percent of the chapters in the SS used this step and it was not used in the HS disciplines at all.

M2S3: Presents the hypothetical statements of the studies:

As such, it was hypothesized that heat affects magnetic and electrical properties of yttrium iron garnet. (Chemistry)

This step was optional in both the HS and SS. Scrutinizing the texts revealed that the use of M2S3 was not a concomitant occurrence of other M2's steps. In other words, as a way of communication, whenever M2S3 was found in the texts, the other steps of M2 were not used.

M2S4: Reports the procedures or methodological techniques that were employed in the production of data:

Polypyrrole/MMT nanocomposites (Ppy/MMT) have been prepared through chemical oxidation using different concentration of pyrrole monomer and ferric (III) chloride ( $\mathrm{FeCl}_{3}$ ) with 1\% (volume/weight) of montmorillonite clay (MMT) in aqueous medium. (Chemistry)

M2S4 is one of the most frequently found steps in this study. This step was evaluated obligatory because all the 40 texts in the HS and SS disciplines explained and clarified the utilized methodological techniques by using this rhetorical unit. One possible explanation for the high frequency of occurrences of this step may be linked to the nature of this rhetorical unit. In other words, by the use of M2S4, students emphasized the validity of their research findings. Therefore, they relied too much on background information of their study and consequently provided more explanation about the utilized methodology.

M3: Explains and justifies procedures or methodology of the research. M3 with a frequency of occurrence of 170 accounted for 6.05 per cent of the moves in the corpus. The frequency of occurrence of this move in both the HS and SS was equally 85 (cf. Table 1). The use of this move may be interpreted as an indicator that student writers perceive that their results could not adequately and convincingly speak for themselves. Thus, they needed a good reason for the adopted methodology in order to emphasize that by its application they have obtained the results. 
M3S1: Provides the established facts that had impacts on the choice of the study's procedures:

(6) Langmuir equation can be used to calculate theoretical maximum sorption capacity $q_{\max }\left(\mathrm{mg} \mathrm{g}^{-1}\right)$ and the energy parameter of sorption $K_{L}\left(l \mathrm{mg}^{-1}\right)$. (Chemistry)

M3S1 was obligatory both in the HS (90\%) and SS (80\%). Accordingly, no disciplinary variation was observed in the use of this step.

M3S2: Refers to the findings of previous research that had an influence on the choice of the study's procedures:

(7) Importantly, as suggested by De Vita and Abbott (2002) and Kollias et al. (2008), the estimated coefficients obtained from the regression process represent the relationship between the dependent and independent variables where strong relationship arises when the coefficients are statistically significant larger than one, whereas weak relationship discovered when the coefficients are significantly below one. (Economics)

This step was found to be optional (40\%) in the HS and obligatory (80\%) in the SS. The plausible reason may be that in the HS, the theories and methodologies are stable and more replicable (Hedges 1987, Sargent 1994). For example, a writer in chemistry may refer to the Mendeleev table, which has an unchangeable list of chemical substances with their properties. However, in the SS, there are different theories for a variable or a factor. For example, there are many theories of second language acquisition proposed by different scholars in the field of linguistics (e.g. Krashen's Innatist theory or McLaughlin's Cognitive theory). Therefore, the authors in the SS tend to emphasize, repeat, and remind the reader(s) of the specific theories, the methodologies and the methods they used in their studies.

M4: Reports the obtained results from the studies. M4 was found to be the most frequently found move in the corpus.

M4S1: Informs the reader which data was going to be discussed:

Figure 4.2 shows the screenshot of segment recording section. (English)

It was evaluated as an obligatory rhetorical unit in both groups of texts since it was found in all the dissertations. Almost in all the occurrences of M4S1, the next rhetorical unit (either in the following sentence or embedded in the 
same sentence) referred to the results of the study. Results of the study were communicated by M4S2:

(9) The calculated lattice parameters ( $a, b$ and $c)$ and unit cell volume for the samples are tabulated in Table 5.1. [M4S1] All the samples are determined to be rhombohedral structure with $a=b \neq c, \alpha=\beta=90^{\circ}$ and $\gamma=120^{\circ}$. The lattice parameters of pure LSMO sample with $a=b=5.4889 \AA$ and $c=13.3567 \AA$ are discovered very close to ICDD standard where $a=b=5.4900 \AA$ and $c=13.3560 \AA$ A. [M4S2] (Physics)

M4S2: Provides justification about the validity of the findings. In fact, through this step, the writers communicate with the scientific discourse community. They present their results to contribute to the knowledge of the field:

(10) The percentage of the total workforce between 5-50 people decreases from $18.2 \%$ before CoC to $13.6 \%$ after getting certified. (Economics)

M4S2 was the most frequently used step in the whole corpus of the present study. Since the entire texts used this rhetorical unit to communicate information, M4S2 was classified as an obligatory rhetorical unit both in the HS and SS. M4S2 was a concomitant of some other steps. For example, it was used frequently together with M2S4:

(11) An analysis using SPSS was conducted and the results were outlined [M2S4]. At the level $\alpha=0.05$ of significance, $p$-value equals 0 and is less than 0.05. [M4S2] (English)

The frequent manifestation of M2S4 when presenting the results may imply that student writers focused on the methodology in order to validate their results. In other words, they present a methodology to show that they have gained the results through valid procedures or methods. Another common co-occurrence of M4S2 was with M6S1:

Good correlation between m.c and conductance was only found at $0.52 \mathrm{GHz}$ shown in Figure 5.15. However poor correlations were found between m.cand susceptance for all the selected frequencies [M4S2]. The interaction between electromagnetic waves with sensor and latex is very complex especially in the frequency range used in this work. [M6S1] (Physics)

These co-occurrences can be explained in terms of student writers' efforts to generalize and validate the results of their studies. As such, they immediately connect the results of their studies to the established body of knowledge. As 
other rhetorical units that were concomitants of M4S2, it can be referred to M5S1 and M5S2. Whenever the student writers were concerned about supporting the results of their study, they explained, interpreted, and generalized their results. In fact, the writers presented their subjective explanations on the results after presenting them objectively. The co-occurrence of M4S2 and M5S1 is displayed in the following example from the corpus.

(13) RMSE value in Box-Jenkins and composite model are larger than the econometric model [M4S2]. This is probably because of the ability of econometric model to capture the dynamics of the structural changes in the market due to variation in the fundamentals which are pertinent. [M5S2] (Economics)

The following excerpt from the corpus shows the co-occurrence of M4S2 and M5S2 as well:

(14) The shift in frequency for both the conductance and susceptance with m.c are almost linearly correlated [M4S2]. The negative sign in the frequency shifts suggest the higher the amount of m.cthe more shall the frequency of the peaks of both conductance and susceptance are shifted to the lower frequencies. [M5S2] (Physics)

M4S3: Refers to the presentation of the unexpected results or the results that are contrary to the initial hypothesis of the study. Consequently, the authors suggested to the scientific community that they contributed something novel that might be worth further investigation. The following excerpts from the present study's corpus show how the ESL student writers communicated the differences in their results.

On the contrary, for OPEFB-g-PS/HIPS and crude OPEFB-g-PS/HIPS composites, the hydroxyl group peak shifted to slightly lower frequencies, from $3424 \mathrm{~cm}^{-1}$ to $3364 \mathrm{~cm}^{-1}$ for OPEFB-g-PS/HIPS composite and $3374 \mathrm{~cm}^{-1}$ for crude OPEFB-g-PS HIPS composite. (Chemistry)

In order to highlight the differences, the authors used conjunctions such as 'although', 'however', and 'on the contrary'. M4S3 with an occurrence number of twelve out of 20 texts $(60 \%)$ was considered as an obligatory rhetorical unit in the HS. But it was realized as an optional step in the SS with an occurrence number of ten out of 20 texts $(50 \%)$.

M5: Presents comments on the results. The idea of presenting the results and simultaneously commenting on them is not in agreement with the guideline 
by the Publication Manual of the American Psychological Association (1996: 32-35). However, The Integrated Results and Discussion chapters in this corpus are completely integrated. Besides, Kanoksilapatham's (2005: 280-282) views about presenting results and simultaneously providing comments on the results were in agreement with the findings of the present study.

This view of integrating the two rhetorical units (M4 and M5) in a unified section is also advocated by Ebrahimi and Chan (2013). As a conclusion, by the use of M5, the writers' subjective comments and judgments on the results were presented. M5 with a percentage occurrence of 20.66 per cent was the second most frequently used rhetorical move of the present study. This result is expected, as it has been proposed by Yang and Allison (2003) that the main function of the Results and Discussion chapter is to present the results and provide comments on them. The high frequency of M4 and M5 and the nature of these two moves suggest that scientific findings have a rather limited value unless they are located in a broader context and go beyond the objective presentation of the results of the study.

M5S1: Provides reasons for the findings or explains the results of the study:

This is probably due to the type of resources and activities available in the AKFRA that might not be conducive for the older people to enjoy. (Economics)

This step was used in more than 60 per cent of the texts in both disciplines. Therefore, it was evaluated as obligatory. This step was found to co-occur with M6S1 in some of the sentences of the corpus:

(17) Definitely, the grain boundary increase is due to the surface volume ratio which is inversely proportional to the decrease of grain size [M5S1]. It is known that the density of state represents the effective band of electron hopping at Fermi level. [M6S1] (Physics)

This co-occurrence probably happened because the writers explained the results of their studies in order to connect them to the existing established body of knowledge.

M5S2: Makes generalizations based on the results of the study or interprets the results of the study:

(18) This seems to suggest that visuals in sequenced EST materials have a material impact on students'learning. (English) 
Since M5S2 was used in the Integrated Results and Discussion chapters of all the 40 dissertations (i.e. the entire corpus), this step was found to be obligatory in both the HS and SS.

M5S3: Compares the findings of the study with the findings of other studies or with the proposed hypothesis:

(19) Although the findings of Al-Ani's study and the findings of the present study show similar trend, the density from present experiment are significantly larger than those of Al-Ani. (Physics)

As can be observed from the example, after presenting the results of the study, the authors presented the results of other studies, which could be consistent or inconsistent with the studies. This comparison was used by the student writers to evaluate the findings of their study and consequently move towards supporting their study's hypotheses. This step was used in 80 per cent of the dissertations in both the HS and SS. Therefore, it was evaluated as an obligatory rhetorical unit.

M5S4: Referred to the limitations arising from a specific result obtained from the study. The excerpt below is an example of M5S4:

(20) The use of molar refractivity stresses the role of ionic packing in controlling the refractive index of the glass. (Physics)

Only two dissertations in the HS used this step to communicate limitations of their studies. On the other hand, in the SS, no communication was performed by the use of this step. As a result, this rhetorical unit was evaluated as an optional step in the whole corpus. The reason for the limited number of occurrences of M5S4 is explicable in terms of the fact that most of the writers preferred to discuss the limitations of their studies in the fifth chapter of the dissertations, which is mostly titled as Conclusion chapter (Thompson, 2005).

M5S5: Provides a summary of the whole study, parts of the study, or the results of the study:

(21) ... summarized that using HM during HD gives the highest yield of essential oils, EO (\%) with 0.035 to $0.078 \%$, followed by MELs during WD and DD with 0.029 to $0.049 \%$ and 0.024 to $0.037 \%$. (Physics) 
M5S5 was optional in both types of disciplines. The possible reason for this is that the summary of the study in the dissertations was mostly presented in the last chapter that is the Conclusion chapter.

M6: provides a detailed description of the study. Kanoksilapatham (2005: 283) maintained that by employing M6, the authors "go beyond the results and place their work under the scrutiny of the discourse community".

M6S1: Refers to the general knowledge of the field that was already established and accepted by the discourse community:

Temperature is one of the important reaction parameters for grafting reaction. (Chemistry)

This step was obligatory in both the HS and SS (HS: 95\%; SS: 95\%). Therefore, it may be deduced that going beyond the results of a study was a matter of importance in both types of science disciplines. It may also be interpreted as a way that the students validated their own results by connecting or relating the results to the established body of knowledge.

M6S2: Goes beyond the results and places their work under the scrutiny of the discourse community:

(23) This will improve the complete time in the water heating process using MELs with about 2.3 times faster than HM. (Physics)

M6S2 was optional in both types of disciplines (correspondingly, 50\% and $55 \%$ of the texts in the HS and SS).

M7: Highlights the strengths of the study and defends the research success.

M7S1: Restates the methodologies of the research. This step was mostly used at the end of Integrated Results and Discussion chapter:

As it was explained, the samples of $(\mathrm{ZnO})-(\mathrm{MgO})-(\mathrm{P} 2 \mathrm{O} 5)$ were examined by $X$-ray diffraction methods to confirm its amorphous structures. (Physics)

This step was optional in both science disciplines (in the HS, $20 \%$ of the dissertations used it, and in the SS, $40 \%$ of the dissertations used it). This rhetorical unit was found to be a restatement of M2S4 that was usually used in 
the beginning sections of the texts. This may convey that most authors did not find it necessary to repeat the methodology at the end of the Integrated Results and Discussion chapters.

M7S2: Restates a part or some parts of the findings. The function of this step is to emphasize or explain more about the findings. It was observed that this step was used mostly at the end and in the concluding sections of the chapters:

(25) Later, the companies have to spend around RM3, 801.04 annually for surveillance visit for another four years. (Economics)

This step was optional in both the HS and SS. In the HS, 45 per cent of the dissertations used this step. Comparatively, in the SS, only ten 10 per cent of the dissertations used this step.

M7S3: Refers to previous research:

(26) A study carried out by Razmjoo, Sahragard, and Sadri (2009) was aimed at identifying the relationship between MI, vocabulary learning knowledge and vocabulary learning strategies among Iranian EFL learners. (English)

M7S3 was used in 90 per cent of the dissertations in the HS. As such, it was obligatory in the HS. Comparatively, it was also obligatory in the SS (60\% of the texts). This rhetorical unit is also known to other researchers. However, to the knowledge of the researcher, in the thesis genre, this rhetorical unit was only reported by Hopkins and Dudley-Evan (1988: 118). They notified that referring to previous literature as a way of consolidating results is a typical pattern of communication in Discussion sections.

M7S4: Explains the unexpected findings or findings that were different from the related literature. Moreover, M7S4 provides justification for the differences:

(27) These anomalies could be due to combine effects of orientation polarization, bound water in rubber latex samples, critical frequency of loss factor, conductance and susceptance peaks of unloaded sensor. (Physics)

Only 15 per cent of the dissertations in the HS used this step. But, this step was used in 50 per cent of the dissertations in the SS. Therefore, this step is considered optional in both types of disciplines. 
M7S5: Communicates the overt claims or generalizations arising from results:

(28) Thus, the A site substitution give a crucial impact in tailoring the magnetic mechanism, electrical transport, structural and microstructural to be tuned in colossal magnetoresistance. (Chemistry)

Looking at the above example, it can be seen that the results were presented and explained first (M4S2 or M5S1). Then a general claim was made based on the results. This step was optional in the HS since it was used in 45 per cent of the dissertations, whereas it was obligatory in the SS ( $90 \%$ of the dissertations). This disciplinary variation suggests that in the SS, the authors emphasized their claims more when making generalizations that contributed to the knowledge of disciplines.

M7S6: Provides examples in order to support an argument or strengthen a claim:

The $D D$ and $S D$ are examples of dry methods while the $W D$ and $H D$ are wet methods. (Chemistry)

M7S6 was optional in both HS and SS disciplines (HS: 10\% of the texts; SS: $55 \%$ of the texts).

M8: Presents the limitations of the study with regards to the findings, methodology, and/or the claim made by a study. Percentage of use of M8 was only 0.60 per cent accounting for all the moves of the corpus. Kanoksilapatham (2005: 285) commented that the high percentage of occurrences of this move is a sign of the scientists' carefulness and honesty in admitting the limitations of the various aspects of their study. Therefore, based on the above results and Kanoksilapatham's (2005) comment, the low frequency of this move may be interpreted as the authors' lack of consideration and confidence in admitting the limitations of their studies.

Regarding the present study's results, as another interpretation of Kanoksilapatham's (2005) remarks, it may be deduced that the student writers did not intend to critique their studies in order to avoid affecting or questioning the validity of their research. Finally, another reason for a limited number of occurrences of this step may be attributed to Thompson's (2005) guide to thesis writing, which suggested that limitations of a study can be presented in the Conclusion Section. 
M8S1: Presents limitations regarding the findings of the study:

(30) Pronunciation of $/ w /$ within a word posed more difficulty for learners diagnosed with slip of tongue. However, these participants were not exempted in the study. (English)

As an optional step, M8S1 was only found in two dissertations in the SS. This step was not used in the HS. Thompson (2005) stated that limitations of a study should be communicated in an independent chapter of dissertations. Consequently, the low frequency of occurrence of M8S1 can be interpreted as evidence that student writers preferred to write based on Thompson's (2005) guide and reported the limitations of their studies in the last chapter of their dissertations.

M8S2: Presents limitations about the methodology of the study:

(31) The only aspect of scaffolding that the software is not able to comply with fully is face-to-face interaction with peers (fellow learners), unless it is used in pairs or groups where learners observe each other's progress. (Language)

This step was found in 20 per cent in the HS and SS dissertations. Therefore, it was registered as optional.

M8S3: Presents the limitations regarding the claims they made:

However, as parameter resetting, by hypothesis, is deemed impossible, some other process or processes might have taken place. (English)

M9: Makes suggestions for future research in relation to the topic of the research:

(33) To improve the setup of this research a microwave oven that has a rotation mechanism, such as a moveable tray should be used. (Physics)

M9 was not found in the SS' texts. It was optional in both HS and SS. There are two possible reasons for the low occurrences of this move. The first reason is that suggestions for the future research are mostly communicated in the last chapter of the dissertations, that is Conclusion chapter (Thompson 2005). Another possible reason, as it is attested by Berkenkotter and Huckin (1995), is that researchers themselves prefer to conduct a particular research instead of explicitly suggesting it to other researchers. 


\section{Conclusion}

To conclude, the findings of the study revealed that Integrated Results and Discussion chapters comprised nine moves. Besides, it was clarified that some subrhetorical units or steps constituted some of the moves. According to the findings of the study, Integrated Results and Discussion chapters focused on presenting the results of the study by communicating in M4 followed by commenting on the gained results, which constituted Move 5. These two moves together with their sub-units or steps constituted the most frequently used rhetorical units of the investigated texts. On the other hand, M8 and M9 were the least frequently used rhetorical units, which indicated that the ESL student writers preferred to communicate these two rhetorical units in the last chapters (Conclusion) of the dissertations. It was also revealed that because of the size of the dissertations, the writers need to remind the readers of the methodology, or objectives of the study. They firstly referred to a specific objective (M2); then they repeated what tools or method they used to reach the objective (M3). Then, they presented the results objectively (M4), and commented on the results subjectively (M5).

Disciplinary variations, in terms of obligatory and optional steps, were observed in M3S2, M4S3, and M7S5. In the HS, M3S2 and M7S5 were obligatory. But they were found to be optional in the SS. On the other hand, in the SS, M4S3 was obligatory, but in the HS, it was optional. The plausible reasons for these variations may be the difference between the nature of theories and methodologies in the HS and SS and the laboratory-based nature of HS studies.

As mentioned before, one benefit of writing results and discussion as an integrated chapter is that, from the author's side, it is easier to write this chapter. When the two chapters are separated, the authors have to make many crossreferences between specific parts of result(s) and specific parts of discussion(s). Moreover, from the reader's side, it is easier to read and follow the contents when the results and discussion are integrated. In a nutshell, in line with Hyland (2004), the findings of the present study are congruent with the argument that move analysis critically evaluates texts and increases readers' awareness of how a text works and communicates efficiently to convey the meaning. As such, the results obtained from the study are useful for students studying in different disciplines and ESP (English for Specific Purposes) teachers and thesis writing courses. Besides, the results of the study may give a pedagogic utility to ESP teachers who teach reading comprehension to develop reading materials since knowledge of the genre conventions is of relevance for assisting them. 


\section{References}

Al-Buainain, H. (2011) 'Students' writing errors in EFL: A case study.' QNRS Repository 2011(1), 2601.

Al-Zubaidi, N. A. G. (2013) 'Analyzing the rhetorical structure of linguistics dissertation abstracts written by Iraqi EFL graduates.' AL-USTATH 204/2, 1-32.

Atai, M. R. and Falah, S. (2005) 'A contrastive genre analysis of result and discussion sections of applied linguistic research articles written by native and non-native English speakers with respect to evaluated entities and ascribed values.' Retrieved May, 2010, from http:/www.paaljapan.org/ resources/proceedings/PAAL10/pdf.

Arulandu, M. (2006) A Genre Analysis of Masters and Doctoral Dissertation Introductions in the Sciences and Social Sciences. Unpublished dissertation thesis. University Putra Malaysia, Malaysia.

Berkenkotter, C. and Huckin, T. N. (1995) Genre Knowledge in Disciplinary Communication: Cognition/Culture/Power. Hillsdale, NJ: Lawrence Erlbaum.

Bhatia, V. K. (2001) 'Analyzing genre: Some conceptual issues.' In: M. Hewings (ed.) Academic Writing in Context: Implications and Applications. Birmingham: University of Birmingham Press. 79-92.

Biber, D., Connor, U. and Upton, T. (2007) Discourse on the Move: Using Corpus Analysis to Describe Discourse Structure. Amsterdam: John Benjamins.

Brett, P. (1994) 'A genre analysis of the results section of sociology articles.' English for Specific Purposes 13/1, 47-59.

Dong, Y. R. (1998) 'Non-native graduate students' thesis/dissertation writing in science: Self-reports by students and their advisors from two U.S. institutions.' English for Specific Purposes 17/4, 369-390.

Duderstadt, J. J. (2000) 'A choice of transformations for the 21 st-century university.' The Chronicle of Higher Education 46, B6-B7.

Ebrahimi, F. and Chan, C. S. H. (2013) 'Manifestation of theme as a point of departure in the result and discussion section of academic research articles.' Pertanika Journal of Social Sciences \& Humanities, 21/spec. November, 29-40.

Fallahi, M. and Erzi, M. (2003) 'Genre analysis in language teaching: An investigation of the structure of the discussion section of language-teaching-journal articles.' Iranian Journal of Applied Linguistics 6/1, 69-81. Retrieved from http://www.sid.ir/en/ VEWSSID/J_pdf/87620030105.pdf.

Hedges, L. V. (1987) 'How hard is hard science, how soft is soft science? The empirical cumulativeness of research.' American Psychologist 42/5, 443-455.

Holmes, R. (1997) 'Genre analysis, and the social sciences: An investigation of the structure of RA Discussion sections in three disciplines.' English for Specific Purposes 16/4, 321-337.

Hopkins, T. and Dudley-Evans, T. (1988) 'A genre-based investigation of the discussion section in articles and dissertations.' English for Specific Purposes 7, 113-122.

Hyland, K. (2004) Genre and Second Language Writing. Michigan: University of Michigan Press.

Kanoksilapatham, B. (2005) 'Rhetorical structure of biochemistry research articles.' English for Specific Purposes 24/3, 269-292.

Kanoksilapatham, B. (2007) 'Writing scientific research articles in Thai and English: Similarities and differences.' Silpakorn University International Journal 7, 172-203.

Kennedy, G. (1998) An Introduction to Corpus Linguistics. London: Addison Wesley Longman. 
Li, Y. (2011) 'A genre analysis of English and Chinese research article abstracts in linguistics and chemistry.' Retrieved from http://sdsu-dspace.calstate.edu/ handle/10211.10/1128.

Nwogu, K. (1997) 'The medical research paper: Structure and functions.' English for Specific Purposes 16/2, 119-138.

Ooi, V. (2001) 'Investigating and teaching genres using the World Wide Web.' In: M. Ghadessy, Henry, A. and Roseberry, R. L. (eds) Small Corpus Studies and ELT. Amsterdam: John Benjamins. 175-203.

Paltridge, B. (2002) 'Thesis and dissertation writing: An examination of published advice and actual practice.' English for Specific Purposes 21/2, 125-143.

Posteguillo, S. (1999) 'The schematic structure of computer science research articles.' English for Specific Purposes 18/2, 139-160.

Publication Manual of the American Psychological Association. (1996) $4^{\text {th }}$ ed. Washington, DC: American Psychological Association.

Salmani Nodoushan, M. A. (2011) 'A structural move analysis of discussion sub-genre in applied linguistics.' Daco Romania, 17/2. 199-212.

Sargent, P. (1994) 'Design science or nonscience.' Design Studies 15/4, 389-402.

Schiffrin, D., Tannen, D. and Hamilton, H. E. (2003) (eds) The Handbook of Discourse Analysis. Oxford, UK: Blackwell Publishing Ltd.

Stoller, F. and Robinson, M. (2013) 'Chemistry journal articles: An interdisciplinary approach to move analysis with pedagogical aims.' English for Specific Purposes $32 / 1,45-57$.

Swales, J. (1990) Genre Analysis. Cambridge UK: Cambridge University Press.

Thompson, P. (2005) 'Points of focus and position: Intertextual reference in PhD theses.' Journal of English for Academic Purposes 4/4, 307-323.

Thompson, P. (2012) 'Thesis and dissertation writing.' In: Paltridge, B. and Starfield, S. (eds) Handbook of English for Specific Purposes. Boston: Wiley-Blackwell. 283-300.

Upton, T. and Connor, U. (2001) 'Using computerized corpus analysis to investigate the textlinguistic discourse moves of a genre.' English for Specific Purposes 20, 313-329.

Weissberg, R. and Buker, S. (1990) 'Writing up research: Experimental research report writing for students of English.' Prentice-Hall, Inc. Retrieved from http://www. getcited.org/pub/102920611.

Yang, R. and Allison, D. (2003) 'Research articles in applied linguistics: Moving from results to conclusions.' English for Specific Purposes 22/4, 365-385.

Yang, R. and Edwards, C. (1995) 'Problems and solutions for trainee teachers reading academic articles in English.' In: Tickoo, M. L. (ed.) Reading and Writing: Theory into Practice (Anthology Series 35). Singapore: Regional Language Centre. 366-382. 
Zahra Shirian Dastjerdi is a Lecturer of ESP courses at Hasht Behesht Institute of Higher Education and Ragheb Isfahani Institute of Higher Education in Isfahan, Iran. She is the reviewer of the International Journal of Education and Literacy Studies. She has authored four papers in international and national journals and presented her papers in two international conferences. She participated as the chairperson in the 2nd Postgraduate Conference of Faculty of Languages and Linguistics in Kuala Lumpur, Malaysia. Her area of interest is discourse analysis, second language acquisition and learning, genre analysis, grammar, and action research.

Address: Zahra Shirian Dastjerdi, Ph.D., Social Sciences Department, Ragheb Isfahani Institute of Higher Education, Basij Street, Imam Khomeini Highway, Isfahan Province, Iran. [e-mail: z_shirian@yahoo.com]

Helen Tan is a Senior Lecturer at the Department of English, Faculty of Modern Languages and Communication, Universiti Putra Malaysia. She has authored and co-authored 42 articles in national and international journals. Her fields of interest include applied linguistics and English studies.

Address: Helen Tan, Ph.D., Department of English, Faculty of Modern Languages and Communication, Universiti Putra Malaysia, Serdang, Selangor, Malaysia. [e-mail: helen@upm.edu.my]

Ain Nadzimah Abdullah is Professor at the Department of English, Faculty of Modern Languages and Communication, Universiti Putra Malaysia. She has been the deputy dean (Graduate Studies and International Affairs) of the Faculty of Modern Languages and Communication, UPM in Malaysia since 2011 and deputy director (Networking and Social Computing) of IDEC at UPM since 2010. Her fields of interest are language planning and policy and language contact, maintenance, and shift.

Address: Ain Nadzimah Abdullah, Professor, Department of English, Faculty of Modern Languages and Communication, Universiti Putra Malaysia, Serdang, Selangor, Malaysia. [e-mail: ain@upm.edu.my] 
